\title{
DO WE STILL NEED A LABORATORY TO STUDY ADVANCED OXIDATION PROCESSES? A REVIEW OF THE MODELLING OF RADICAL REACTIONS USED FOR WATER TREATMENT
}

\begin{abstract}
Environmental pollution due to humankind's often irresponsible actions has become a serious concern in the last few decades. Numerous contaminants are anthropogenically produced and are being transformed in ecological systems, which creates pollutants with unknown chemical properties and toxicity. Such chemical pathways are usually examined in the laboratory, where hours are often needed to perform proper kinetic experiments and analytical procedures. Due to increased computing power, it becomes easier to use quantum chemistry computation approaches (QCC) for predicting reaction pathways, kinetics, and regioselectivity. This review paper presents QCC for describing the oxidative degradation of contaminants by advanced oxidation processes (AOP, i.e., techniques utilizing $\bullet \mathrm{OH}$ for degradation of pollutants). Regioselectivity was discussed based on the Acid Blue 129 compound. Moreover, the forecasting of the mechanism of hydroxyl radical reaction with organic pollutants and the techniques of prediction of degradation kinetics was discussed. The reactions of $\bullet \mathrm{OH}$ in various aqueous systems (explicit and implicit solvation) with water matrix constituents were reviewed. For example, possible singlet oxygen formation routes in the AOP systems were proposed. Furthermore, quantum chemical computation was shown to be an excellent tool for solving the controversies present in the field of environmental chemistry, such as the Fenton reaction debate [main species were determined to be: $\cdot \mathrm{OH}<\mathrm{pH}=2.2<$ oxoiron(IV)]. An ongoing discussion on such processes concerning similar reactions, e.g., associated with sulphate radical-based advanced oxidation processes (SR-AOP), could, in the future, be enriched by similar means. It can be concluded that, with the rapid growth of computational power, QCC can replace most of the experimental investigations related to the pollutant's remediation in the future; at the same time, experiments could be pushed aside for quality assessment only.
\end{abstract}

Keywords: advanced oxidation processes, water treatment, wastewater treatment, Fenton process, radical chemistry, singlet oxygen, Density Functional Theory (DFT), quantum chemical computations

\section{Introduction}

The fast development of the industrial sector and the irresponsibility of human actions have caused ubiquitous pollution in the world [1]. The increasing amount of contamination, especially contaminants of emerging concern (CEC) and persistent organic pollutants (POPs), are urging scientists to discover new methods of their elimination as well as the determination of their fate [2]. For the elimination of persistent compound often the sole biological processes (e.g., bioremediation, activated sludge treatment) are insufficient [3-8] and more invasive treatments are recommended that can be divided universally into physical and chemical remediations [3]. Advanced oxidation processes/techniques (AOP) depend on $\bullet \mathrm{OH}$ (hydroxyl radical) reactions that are generated from various precursors that

\footnotetext{
${ }^{1}$ Institute for Nanomaterials, Advanced Technologies and Innovation, Technical University of Liberec, Studentská 1402/2, 46117 Liberec 1, Czech Republic, phone +420 485353 389, email: stanislaw.waclawek@ tul.cz
} 
can be applied in situ for chemical oxidation (ISCO) of contaminants. Recently, sulphate radical-based advanced oxidation processes (SR-AOP) have gained popularity where the $\mathrm{SO}_{4}{ }^{-}$(sulphate radical) is a primary oxidant instead of a hydroxyl radical [9, 10]. These methods are extensively used to remove chlorinated aliphatic and aromatic compounds, CEC and POPs [11].

Transformation of the pollutants either by anthropogenic (e.g. in situ remediation) or natural ways, is controlled by reaction kinetics, which can normally be determined experimentally by measurements of the concentration of a compound over time. However, to perform experiments to assess a single value of kinetic rate constants, a lot of labour is required (and lots of additional waste is generated). Moreover, the contaminants of emerging concern are already present in such numbers in water treatment systems (particularly water reuse and wastewater) that experiments to assess their reaction sites, kinetics and products are almost impossible to perform [12].

Fortunately, it was found that experiments are not the only way of predicting the reaction mechanism and kinetics [12]. A quantum chemical calculation (QCC) offers a strategic basis for achieving these targets with the bonus of not needing a massive database (and not generating considerable amounts of waste when performing the experiments). Besides, the energies computed by QCC can have an accuracy of $<2 \mathrm{kcal} / \mathrm{mol}$, which is similar to that of many of those determined experimentally [12]. QCC can also be used for many other tasks other than the degradation of pollutants, such as studying the modification of nanomaterials [13], determining the reaction mechanism with DNA components [14-17] and other biomolecules present in a mammal's body [18-20].

a)

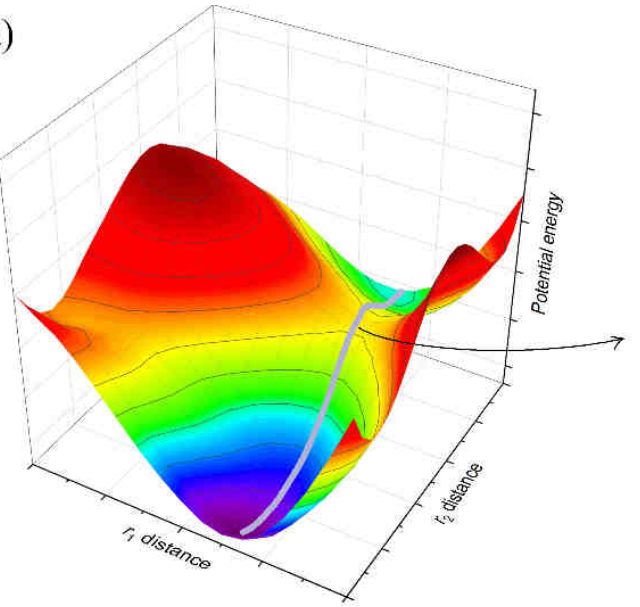

b)

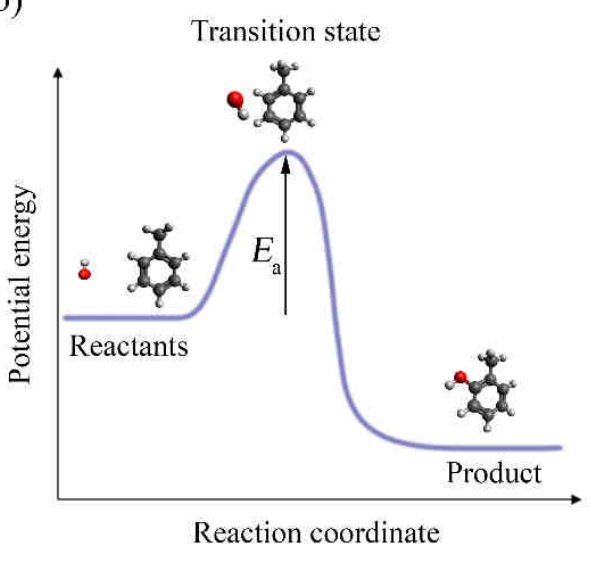

Fig. 1. a) Model potential energy surface showing an example of a reaction path, minima, and transition state, b) the same but in one dimension. The transition state structure is only an example; however, the product of the reaction of hydroxyl radical and toluene was indeed determined by QCC to be $o$-cresol [21]. Molecules were visualized with the Avogadro program $(\mathrm{H}, \mathrm{C}, \mathrm{O}$ atoms represented by white, black and red colours, respectively)

QCC for estimating a molecule's chemical properties needs a molecule structure as an input to various software programs. The chemical properties of the molecule are given as an output, such as the highest occupied molecular orbital (HOMO) energy, the lowest 
unoccupied molecular orbital (LUMO) energy, a dipole moment, and total electronic energy, just to name a few [22]. In more detail, QCC relies on the isolation of single molecules or compounds [more atoms (electrons to be more precise) during the computation translates to a longer computation time].

As an input for QCC, several pieces of information are required:

1. The type $(\mathrm{H}, \mathrm{C}, \mathrm{O}, \ldots)$ and coordinates $(r)$ of atoms (for a required compound, a guess structure can be generated by software [23]).

2. Information on the total charge of a compound (e.g., 0 for neutral substances, -1 for anions, -2 for dianions, +1 for cations etc.)

3. Information on the total multiplicity (e.g., 1 for closed-shell, 2 for radicals).

The approximate solution of the time-independent electronic Schrödinger equation, which can give us potential energy for such a system, depends upon the $r$ (lengths, angles, torsion angles of the bonds) from the input file. QCC is ideal for determining the potential energies of substrates and products as well as transition states (TS) [12] (Fig. 1).

This information can be obtained to predict the detailed mechanism of the reactions discussed in the next sections (Fig. 2).

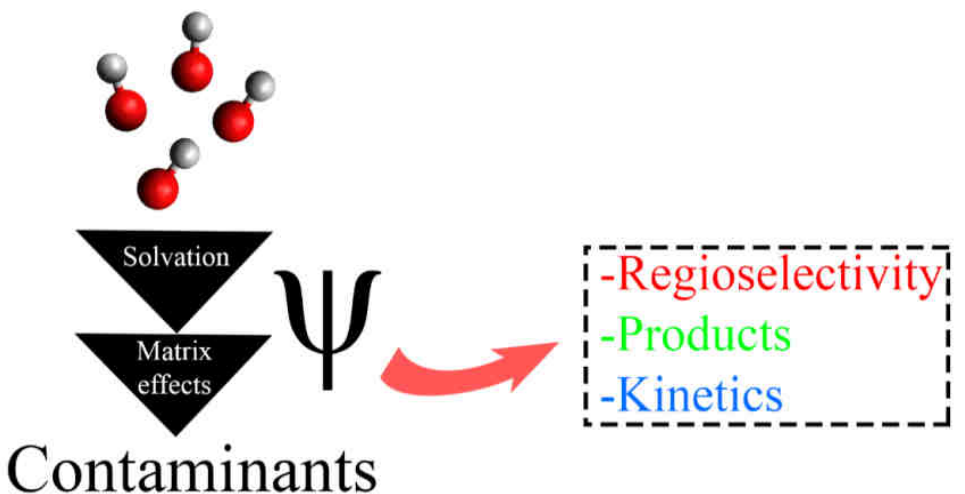

Fig. 2. Scheme presenting possible uses of QCC in AOP reactions (the molecules in the figure represent hydroxyl radicals)

There are many freeware and commercial computer programs [24, 25] for converting the input files into the outputs possessing useful information on the compound of interest. Such software uses modern electronic structure methods, offering approximate solutions to the Schrödinger equation, which can be divided into two groups: methods based on wave function and methods based on density functional theory (DFT). However, in this review paper, we will not focus on describing the theory behind QCC and the proper levels of theory for the desired reaction types since excellent articles have already been published on such topics $[12,26]$. The purpose of this review paper is to show some of the capabilities (useful for environmental scientists) of QCC that can not only supplement experimental studies but, in some cases, reliably replace them.

\section{Regioselectivity and products' formation}

By QCC it is possible to some extent to determine various reactive sites (regioselectivity). The Schrodinger equation's wave function has descriptors to predict the 
locations most prone to oxidation reactions (also reduction) in target compounds. Xiao et al. often only uses (and with success) HOMO and LUMO for determining the reactive centers of organic molecules [27]; (the HOMO is naturally often recognized as a site for electrophilic attack, whereas the LUMO - for nucleophilic attack). Notably, many more specific reactivity descriptors can often be reasonably approximated by HOMO distribution.

An extended investigation of our previous work [28] on the Acid Blue 129 (AB129) compound was presented herein. In this specific case, the HOMO and HOMO-1 of AB129 seem to be largely delocalized, making it more challenging to determine the reactive site available for free radicals (Fig. 3).

HOMO

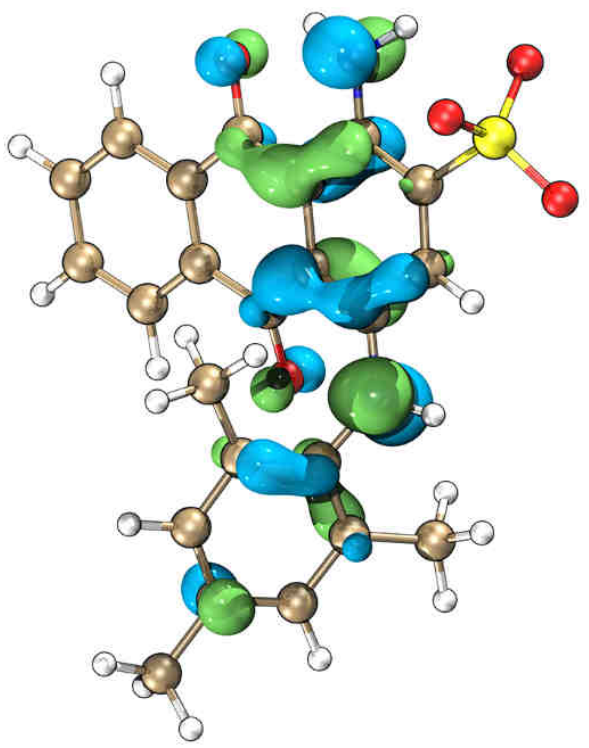

HOMO-1

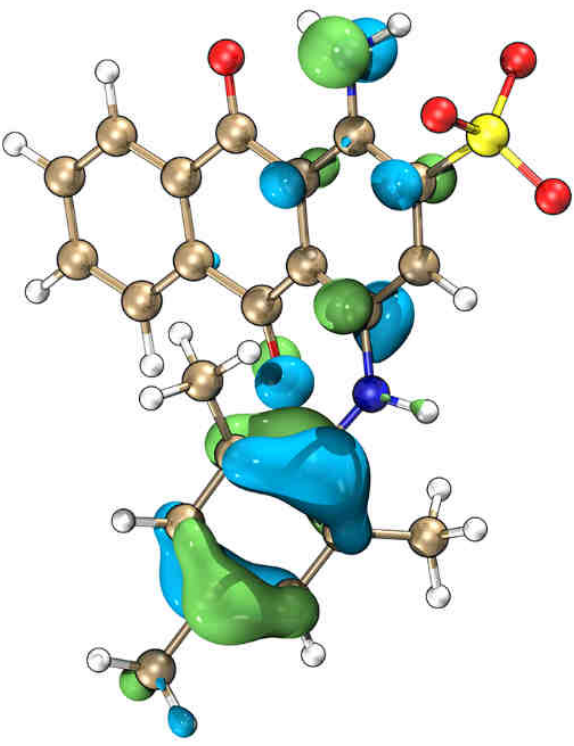

Fig. 3. HOMO and HOMO-1 of the AB129. These were examined (with Gaussian 16 software) by DFT calculations at the B3LYP/6-31+G* level. Solvation model: SMD. The data were elaborated by Multiwfn software [29], whereas the cube files were rendered by VMD software [30, 31]. The green and blue colours represent positive and negative phases. Isovalue: 0.05 . Atoms $\mathrm{H}, \mathrm{C}$, $\mathrm{N}, \mathrm{O}, \mathrm{S}$ are shown as white, gold, blue, red, and yellow, respectively

Although when based only on HOMO distributions it is difficult to determine the reactive sites, it can be assumed that an electrophilic attack will probably occur somewhere within the vertical axis (Fig. 3) of the AB129 [28].

In such problematic cases, several other descriptors can be used to help with the assessment of the reactive site. In Figure 4, the natural bond orbital (NBO), average local ionization energy (ALIE), and Fukui function, as well as dual descriptor are presented. An NBO can be assigned to one atom (lone pair) or two atoms (bonds), and the (above-mentioned) delocalization problem can be overcome. The ALIE is the average 
energy necessary to remove a single electron from a point in space. The Fukui function can reveal the reactive sites for electrophilic attack $f^{-}$, nucleophilic attack $f^{+}$and radical attack $\left(f^{0}\right)$. Whereas the dual descriptor $\Delta f$ is closely related to the Fukui function: $\Delta f(\mathrm{r})=f^{+}(\mathrm{r})-f^{-}(\mathrm{r})$.
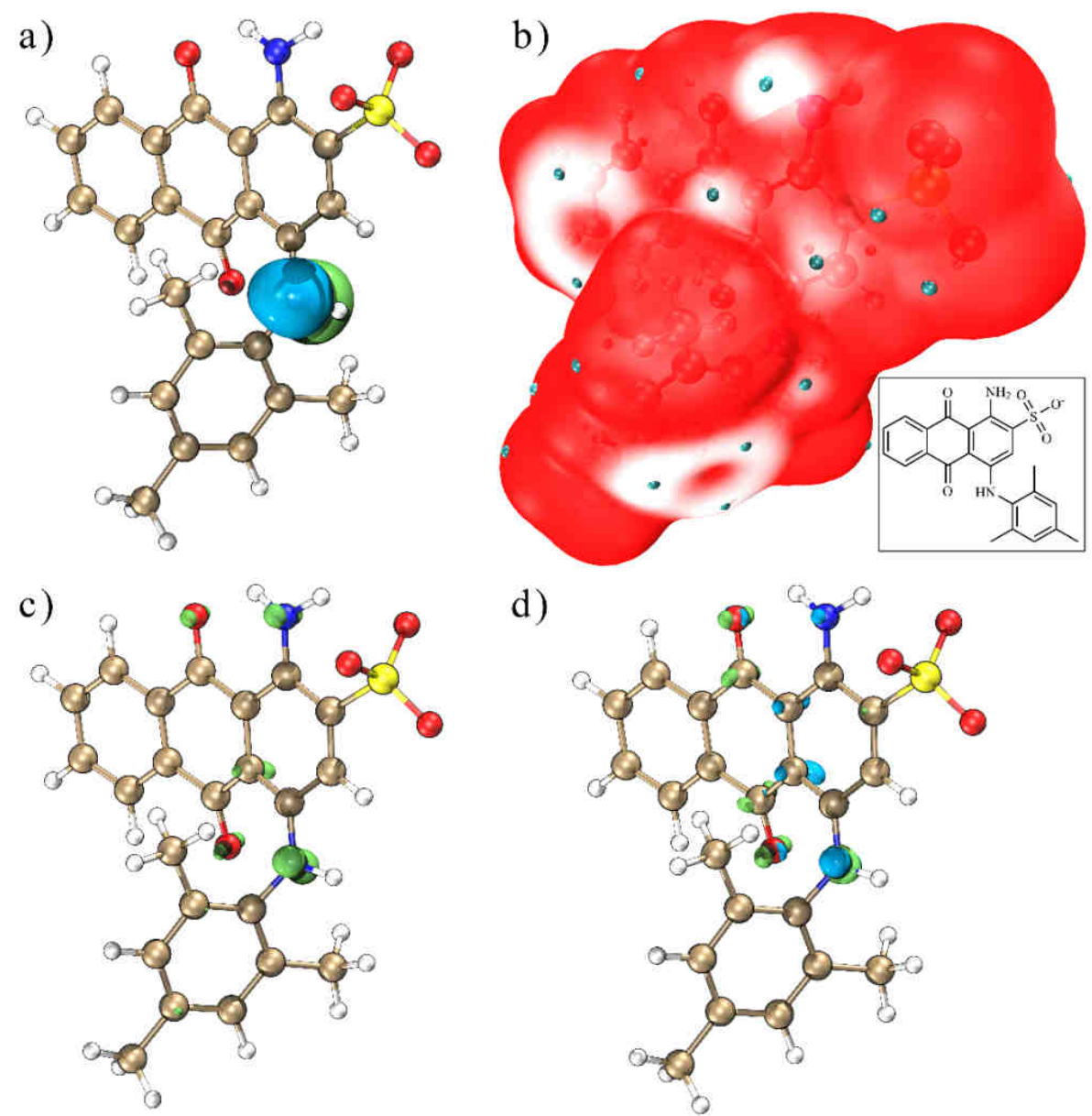

Fig. 4. a) Natural bond orbital (NBO) of a -NH- nitrogen lone pair (isovalue: 0.05), b) average local ionization energy (ALIE) analysis [inset shows the 2D model of AB129], white spots (and cyan spheres) showing the regions with a low ALIE value (isovalue: 0.0005), c) Fukui function $f^{-}$ (isovalue: 0.008), d) the dual descriptor $\Delta f$ (isovalue: 0.008) of the Acid Blue 129 compound. Examined (with Gaussian 16 software) by density functional theory (DFT) calculations at the B3LYP/6-31+G* level (ALIE was examined at M11/6-31+G** level); solvation model: SMD. Data were elaborated by Multiwfn software [29], whereas the cube files were rendered by VMD software [30, 31]. Green and blue colours represent positive and negative phases/values, respectively. Atoms $\mathrm{H}, \mathrm{C}, \mathrm{N}, \mathrm{O}, \mathrm{S}$ are shown as white, gold, blue, red, and yellow, respectively

The most significant contribution to the HOMO was located on the nitrogen of the -NH- group. The NBO of this nitrogen's lone-pair electrons can be seen in Figure 4a. It is 
also qualitatively visible that this NBO dominates the $f^{-}$(Fig. 4c). Thus, it can be concluded that the $f^{-}$is mainly composed of lone pair electrons of the - $\mathrm{NH}$ - group of AB129 (calculated contribution of HOMO to $f^{-}$was estimated to be $71 \%$ ). On the other hand, ALIE analysis (Fig. 4b) was determined as a good descriptor for the prediction of the reactive sites [12]. The area with the lowest ALIE on the surface is generally known as the most vulnerable site to electrophilic or free radical attacks. The low value of ALIE means that the electron is not strongly bound at this position. In our case, however, this analysis indicated the $-\mathrm{NH}_{2}$ functional group as the most favourable for electron loss. Nonetheless, a low ALIE value could also be found near the - $\mathrm{NH}$ - group and the aromatic rings. A Fukui function and the dual descriptor were thus used to gain further insight into the most reactive site for the electrophilic attack. The dual descriptor can also be approximated based on the spin density of $\mathrm{N}$ (total number of electrons)-1, which was presented as a reactivity descriptor in a recent paper [12]. The most positive part of $f^{-}$is located on the -NH- group, indicating the most probable site for the electrophilic attack on the AB129 compound. Unlike the Fukui function, both types of reactive sites can be revealed simultaneously via the dual descriptor. It is claimed that if $\Delta f>0$ (in Fig. 4 green surface), then the site is favourable to a nucleophilic attack, whereas if $\Delta f<0$ (in Fig. 4 blue surface), then the site is favourable to an electrophilic attack. Similar to $f^{-}$, the -NH- group was also depicted by the dual descriptor as the most reactive site with oxidizing agents. In conclusion, the two most probable areas susceptible to the oxidative radical attack can be chosen from the above analysis, i.e., $-\mathrm{NH}-$ and $-\mathrm{NH}_{2}$ groups.

In order to obtain more of the quantitative results to gain further insight into the AB129 reactivity in AOP systems, Table 1 presents the condensed functions, including $f^{0}$ (indicating the most probable radical attack), comparing the two most probable nucleophilic sites (-NH- and $\left.-\mathrm{NH}_{2}\right)$.

Table 1

Values of various descriptors indicating the most possible radical/electrophilic attack sites

\begin{tabular}{|c|c|c|c|c|c|}
\hline & $\boldsymbol{E}_{\text {NBo }}[\mathbf{e V}]$ & ALIE $[\mathrm{eV}]$ & $\boldsymbol{f}^{-}\left[\mathbf{e}^{*}\right]$ & $\boldsymbol{f}^{\mathbf{0}}\left[\mathbf{e}^{*}\right]$ & $\boldsymbol{\Delta}\left[\mathbf{e}^{*}\right]$ \\
\hline $\mathbf{- N H}_{\mathbf{2}}$ & -7.52 & 11.4 & 0.0592 & 0.0464 & -0.0256 \\
\hline -NH- & -6.86 & 12.8 & 0.0824 & 0.0539 & -0.0571 \\
\hline
\end{tabular}

* elementary charge

Almost all descriptors indeed indicate that the - $\mathrm{NH}$ - group could be the most reactive with oxidants. However, it should be noted that except for $E_{\mathrm{NBO}}, f^{-}, f^{0}$ and $\Delta f$, which indicate - $\mathrm{NH}$ - as the most reactive site for oxidative reactions, the average local ionization energy descriptor indicates that the $-\mathrm{NH}_{2}$ group has the weakest electron-binding ability. ALIE is often used to complement electrostatic potential (EP) analysis to unravel the possible radical susceptible sites, where EP shows the regions to which an approaching electrophile will initially be attracted, and ALIE indicates how available the electrons are at these and other areas [32]. AB129 possess EP maxima $(-0.47 \mathrm{eV}$, calculated at the same level of theory as ALIE) near the -NH- functional group, indicating a higher affinity of negatively charged oxidants towards this area, such as sulphate radical $\left(\mathrm{SO}_{4}{ }^{-}\right)$. Our group has already experimentally determined that this is precisely what happens, i.e., the sulphate radical reacts selectively with the $-\mathrm{NH}$ - group [28]. The reason why the $\mathrm{AB} 129-\mathrm{NH}_{2}$ group is not the most reactive with the radicals, as indicated by ALIE analysis, could be trivially explained by the protonation of this group, which is possible in acidic and neutral $\mathrm{pH}$ 
values [33]. When performing ALIE analysis of the AB129 with a protonated amino group $\left(-\mathrm{NH}_{3}{ }^{+}\right)$, the surface minima disappears from that region.

Although, as shown, QCC can successfully be used to determine the reactive sites, its use for predicting transformation products generated from contaminants during oxidative water treatment is still challenging [12]. However, as presented in many studies, qualitative conclusions can be drawn. One of the simplest ways of getting information on what types of intermediates can be formed is the so-called short-cut method [34]. The thermodynamically favourable process can be determined by the fact that it leads to the creation of a lower energy product than the initial reactant. This information could be utilized to calculate the probability of the formation/type of by-products. For example, in the work presented by Zhang et al. [35], an in silico model for revealing oxidation mechanisms of contaminants (by ozone) was presented. Sulphamethoxazole (SMX) was selected as a model compound. SMX oxidation products were predicted on the basis of their Gibbs free energies $(\Delta G)$. Moreover, experiments conducted have confirmed the formation of these products. A similar case was researched in ref. [36], where QCC was used to support the determination of the products of trimethoprim oxidation. Both sets of data obtained in the experiments and the supporting QCC showed that methylene-hydroxylated and methoxy-containing phenyl ring hydroxylated transformation products were produced $[36,37]$.

As a side note, a helpful tool (especially for following the reactions of dyes) is the ability of computational approaches to determine excitation energies and oscillator strengths of the molecules. This utility allows the creation of theoretical UV-Vis / infrared (etc.) spectra, facilitating the determination of reaction products without more sophisticated instruments such as mass spectrometry [28]. For example, the theoretical spectra of AB129 (studied here) was determined to be $594 \mathrm{~nm}$, which matches the experimentally-obtained value $(595 \mathrm{~nm})$ almost exactly [28]. Similarly, the spectra of by-products/final products can be calculated. It is worth mentioning that recently developed Similarity Transformed Equation of Motion CCSD (STEOM-CCSD) was shown as a great alternative to a conventionally used time-dependent density functional theory (the accuracy of the theoretical UV-Vis spectra prediction can be substantially improved with only a slight computational cost increase) [38].

\section{Determining the transition states and kinetics}

More detailed studies can be done when information on potential reactive sites, approximate transition states, and products are available. For example, the radical mechanism can be explained. These reactions are so rapid that it is often exceedingly difficult to follow them by experimental methods. For instance, in the AOP, complex-peroxyl radical reactions can create similar transition products, making it almost impossible to research the elementary reaction mechanisms and kinetics experimentally [39]. When the information about reactants and products are available, there are several algorithms that allow for finding the transition state (e.g. QST2 in Gaussian). Intrinsic reaction coordinate (IRC) analysis is the usual technique used to verify that each found transition state uniquely links the reactants with either the intermediate and/or the corresponding product species (geometry optimization could converge to the wrong TS if the given initial structure is not sufficiently close to the desired TS [40]). To examine the existence of the stationary points calculated and to obtain the corresponding 
thermodynamic properties, frequency calculations can be carried out at the same stage as the optimization; reactant, intermediate and product species correspond to zero imaginary frequencies, while transition state structures correspond to one imaginary frequency.

Radical reactions can generally proceed in three ways: through an addition reaction, $\mathrm{H}$-abstraction and electron transfer [9]. QCC can reveal these mechanisms. For example, the $\bullet \mathrm{OH}$ reactions with thiourea derivatives were determined to proceed via $\mathrm{H}$-abstraction [41]. Moc and Simmie [42] determined the preferential site of the n-butanol H-abstraction by hydroxyl radical. On the other hand, in a different study, the authors found the $\mathrm{OH}$ addition to the benzene ring of diclofenac as the thermodynamically more favourable reaction mechanism than $\mathrm{H}$-abstraction [43]. However, it should also be mentioned that the electron transfer mechanism might not be feasible for potential energy surface computations for TS identifications [12].

When the TS are available and checked by IRC, the rate constants for the reaction pathways can be determined using transition-state theory (TST) and its modified versions (excellent programs for predicting kinetic properties from quantum results are available [44]). One example was provided by the above-mentioned paper by Serobatse and Kabanda [41], who determined the kinetic rate constants between thiourea derivatives and hydroxyl radical by the TST method. Many authors have made similar approaches. For example, TST was used for the determination of $k$ in the reaction of $\bullet \mathrm{OH}$ with naproxen [27], phosphoramidate [45], bisphenol A [46], and many others [2]. Notably, the TST determinations of the kinetic rate constants agree with the experimental values to within a factor of 3-750 ( $\Delta G$ accuracy of $\pm 0.4 \mathrm{kcal} / \mathrm{mol}$ is required to predict the $k$ within a factor difference of 2 from the experimental value using a conventional TST [39]), whereas the quantitative structure-activity relationship (QSARs) methods (discussed below), agreed with the experimental values to within a factor of 2-4 [12].

QSARs approaches use various quantum chemical descriptors discussed in previous sections to calculate the kinetic rate constants through correlation models. The most important descriptors for calculating kinetic rate constants were found to be the orbital eigenvalue of the highest occupied molecular orbital $\left(E_{\mathrm{HOMO}} ;-E_{\mathrm{HOMO}}=\right.$ ionization potential $)$ [12]. Other molecular descriptors relevant for AOP reactions with CEC could include electron-affinity ( $\left.-E_{\mathrm{LUMO}}\right)$, the number of halogen atoms (usually, e.g., more halogenated molecules are less reactive towards oxidants [12]), the number of ring atoms, double bond equivalence [47] and many others [48]. Good QSAR correlations could often be found between the rate constants for the reactions of closely related substances (i.e., that possess the same functional group) $[49,50]$. The rate constants were predicted by QSAR models for many AOP reactions and other types; e.g. between contaminants and hydroxyl radicals [51-53], chlorine, chlorine dioxide, ferrate [49], ozone [48, 49], Fenton process [54], tetra-amido macrocyclic ligand/ $\mathrm{H}_{2} \mathrm{O}_{2}$ [55], peroxone [56] or electro-peroxone [47]. Modelling the kinetic rate constants for the reactions of $\bullet \mathrm{OH}$ with contaminants was also presented on $\mathrm{pH}$ - and temperature-dependent models based on the decision tree boost [57].

Moreover, QCC could be employed even for purposes such as evaluation of the effects of bromide [58] or dissolved oxygen (DO) on the radical oxidation of contaminants. Work determining the DO's impact has confirmed its importance on the oxidation of pollutants, as was observed experimentally [59]. Further a theoretical approach was provided for studying the effects of wastewater components on the decontamination of pollutants in SR-AOPs [60]. This topic is discussed in detail in the next section ("Solvation and matrix effects"). 


\section{Solvation and matrix effects}

As was mentioned, QCC are often used for separated systems, consisting only of several molecules. However, this is not what is happening in real AOP systems, where the enormous effect of the water, dissolved oxygen, precursors of hydroxyl radicals and other water matrix constituents are present. In this section the influence of these effects will be elaborated.

\section{Solvation}

The reactions between $\bullet \mathrm{OH}$ and water have been investigated theoretically for almost 30 years [61-64]. These reactions happen in the atmosphere, and because of this, QCC has been used to gain more information on these reactions [65-69]. Water is known to form complexes with hydroxyl radicals (with stability = bond dissociation energy $\sim 5 \mathrm{kcal} / \mathrm{mol}$ [70]) by delocalizing the lone pair on $\mathrm{O}$ in the water molecule towards $\bullet \mathrm{OH}$ [71]. The $\bullet \mathrm{OH}$ and water react together by exchanging an atom of hydrogen and re-forming the reactants [72]. A water molecule was reported to be a catalyst also for hydroxyl radical reactions [73], due to the enhanced stability of the pre-reactive complex formed. However, some $\bullet \mathrm{OH}$ reactions (e.g. under atmospheric conditions) can be slowed down by the presence of water [74].

In QCC the effect of water solvent on $\mathrm{OH}$ reactions can be studied both explicitly (i.e., the water molecules are added directly to the studied system [75]; Fig. 5a) and implicitly. The solvent is implicitly expressed as a continuum solvent (Fig. 5b).

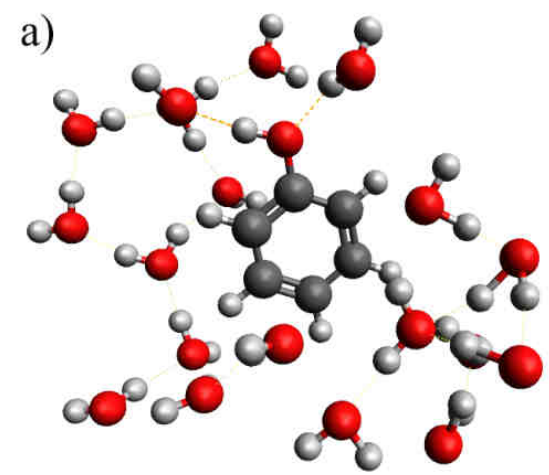

b)

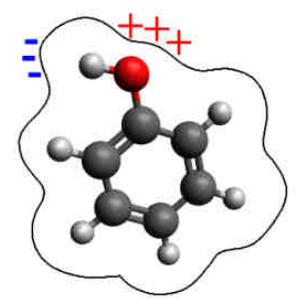

Fig. 5. a) Example of the explicit solvation model by water molecules, which includes specific interactions (H-bonds shown as dashed lines) and b) an example implicit solvation by a dielectric medium with surface tension at the solute-solvent boundary (requires only simple addition of a keyword to the software's input, instead of the explicit addition of water molecules). The most popular and universal solvation model for AOP is SMD [76] (computationally less demanding than the other continuum models [77]). The continuum's polarized "counter-" charges are displayed in red and blue. The molecules were visualized with the Avogadro program [23]

The implicit solvation model has been utilized in many AOP and SR-AOP studies $[28,78]$. However, it should be mentioned that the implicit model does not include specific interactions, for example, hydrogen bonding between the reactants and solvent. A hybrid approach can also be employed, i.e., the addition of a few water molecules to the implicit system, which can improve the precision of calculations primarily for ions [12]. 
As for the explicit models, the precision of such a model depends upon its size, i.e., smaller systems are contaminated by system size effects [79]. However, many authors have decided to study the reactions in the presence of only one water molecule [80]. The reactions in such environments between $\bullet \mathrm{OH}$ and carbonyl oxide [81] and $\mathrm{HOCl}$ [82] have been studied. Such interactions can lead to additional elementary reactions [81] and could be much more complex [82]. The van der Walls bonds between the water and reactant can greatly influence the reaction pathway or do not directly affect the reaction but produce stabilization of the transition states and reactive complexes [81].

Much more complicated systems containing many water molecules and studies of hydroxyl radical reactions were presented [17, 79, 83]. The presence of solvent significantly affects the structures of stationary points in an aqueous solution. Many authors report that the solvent could substantially reduce the height of the free-energy barrier, indicating that an aqueous solution has a catalytic effect on the reaction mechanism and could increase the reactivity of proton transfer in an aqueous solution [17, 79].

\section{Influence of molecular oxygen on the AOP and the interconversion to singlet oxygen mechanism}

The effect of dissolved oxygen on AOP is often neglected in experimental studies. However, based on some theoretical investigations, this could impact the system under examination [39]. In point of fact, a reaction of hydroxyl radical with organic contaminants often generates C-centered radicals, which further react with molecular oxygen to form peroxyl radicals and then decompose to form low-molecular species. The exact mechanism has been studied theoretically [39].

Furthermore, the interactions of a hydroxyl radical with $\mathrm{O}_{2}$ has been studied theoretically by Suma et al. [84]. The bond linking the $\bullet \mathrm{OH}$ and oxygen moieties was determined to be ca. $1.688 \AA$ long with dissociation energy of $3.90 \mathrm{kcal} / \mathrm{mol}$, and the recombination reaction has almost no activation barrier, which could suggest the presence of a certain number of $\bullet \mathrm{OH}-\mathrm{O}_{2}$ complexes during AOP.

Another topic is the formation of singlet oxygen, which, according to many authors, is responsible for many reactions in AOP and SR-AOP [85-88]. This phenomenon was determined theoretically possible, among other phenomena, during the reaction of two hydroxyl radical molecules, which could result in the generation of a triplet oxygen atom, $\mathrm{O}\left({ }^{3} \mathrm{P}\right)$ [89], whose recombination (or the reaction with $\bullet \mathrm{OH}$ ) can result in singlet oxygen formation [90-92]. In addition, hydroperoxyl radical that are present in many AOP systems can recombine with subsequent singlet oxygen formation, which was found by the DFT technique [93]. However, one should remember that these studies did not account for various substances present in standard water matrices, which could significantly influence singlet oxygen yield.

\section{Reactions of $\bullet \mathrm{OH}$ with other water matrix constituents}

The hydroxyl radical reaction with hydrogen peroxide molecule (often a precursor of hydroxyl radicals) by theoretical methods was reported [94]. The hydrogen bonding between the $\mathrm{OH}$ radical and the $\mathrm{H}_{2} \mathrm{O}_{2}$ molecule forms a five-membered ring complex, and its vibrational spectrum was reported. This reaction differs in the presence of water and the calculated rate constant of $\mathrm{H}_{2} \mathrm{O}_{2}$ was in agreement with the experimental values. It was determined that a single water molecule could slow down the reaction substantially [74]. 
On the other hand, halides, such as chloride and bromide, were determined to influence the AOP due to their fast reaction rate with the hydroxyl radicals [9]. These reactions were also investigated by DFT calculations $[95,96]$. In the formation between the $\cdot \mathrm{OH}$ and halide anions $\left(\mathrm{Cl}^{-}, \mathrm{Br}^{-}, \mathrm{I}^{-}\right)$hemibonding was observed. By including four hydrogen-bonded water molecules, equilibrium geometries with hemibonding between the hydroxyl radical and halide anions were found. The free energy reaction values measured for the formation of hydroxyl halide radical anion from the $\bullet \mathrm{OH}$ and halide anion is endothermic for chloride but exothermic for bromide and iodide, which is consistent with the equilibrium constant experimental values. Another work presented how cations and anions $\left(\mathrm{Ca}^{2+}, \mathrm{Mg}^{2+}\right.$, and $\mathrm{Zn}^{2+} ; \mathrm{Br}^{-}, \mathrm{Cl}^{-}$, and $\mathrm{NO}_{3}{ }^{-}$) can influence oxidative reactions. Surprisingly, it was determined that all the selected anions promoted the degradation of sulphamethoxypyridazine by reducing the activation energy of the rate-limiting step [97]. This result accords with some experimental works where the anions positively influenced the oxidation of some substances [9].

Another often-investigated ion influencing AOP and SR-AOP reactions is nitrate. The reaction with a hydroxyl radical of its conjugate acid (nitric acid) was investigated theoretically, and a hydrogen-bonded $\mathrm{OH}-\mathrm{HONO}_{2}$ intermediate was confirmed with an estimated lifetime of $\sim 40$ ps [98]. A similar investigation was the subject of another work [73]. The authors determined that the $\bullet \mathrm{OH}$ is positioned in such a way that the unpaired electron interacts with the lone pair of the NO moiety's oxygen atom and allows one electron to migrate from the lone pair of the NO group's oxygen atom to the $\bullet \mathrm{OH}^{\prime}$ s oxygen.

It can be concluded that the reactions of $\bullet \mathrm{OH}$ with water matrix constituents can be successfully theoretically researched. However, the hydroxyl radical reactions with many anions (sulphates, carbonates) that are normally tested during experimental investigations of AOP were probably not investigated yet theoretically in much detail and could create an interesting scope of study in the future.

\section{The Fenton reaction mechanism controversy}

As determined theoretically [99], hydrogen peroxide should not spontaneously decompose into non-activated radicals; instead, it could donate a proton. This fact could explain how the $\mathrm{O}_{3} / \mathrm{H}_{2} \mathrm{O}_{2}[2,97,100]$ and persulphates $/ \mathrm{H}_{2} \mathrm{O}_{2}$ [9] systems work, involving the deprotonation of $\mathrm{H}_{2} \mathrm{O}_{2}$ to $\mathrm{HO}_{2}^{-}$that further reacts with the oxidants and precedes the formation of the radical.

The Fenton reaction is a reaction between hydrogen peroxide and ferrous iron that yields one hydroxyl ion, oxidized iron, and a hydroxyl radical [101]. The mechanism of this reaction might depend upon the formation of ${ }^{2+}$ metal ions, i.e., simple aqua complexes $\left[\mathrm{M}\left(\mathrm{H}_{2} \mathrm{O}\right) \mathrm{n}\right]^{2+}$ decompose hydrogen peroxide with further radical production by a homolytic $\mathrm{O}-\mathrm{O}$ bond cleavage in the key complex $\left[\mathrm{M}\left(\mathrm{H}_{2} \mathrm{O}\right)_{(n-2)}\left(\mathrm{H}_{2} \mathrm{O}_{2}\right)(\mathrm{OOH})\right]^{2+}[102,103]$. At least, this is the classical and best-known interpretation of the mechanism. However, experimental evidence has emerged that iron in high oxidation states [ferryl ion, $\mathrm{Fe}(\mathrm{IV})$ ] can be formed as reactive oxygen species (ROS) instead of a hydroxyl radical [104] (similarly to the reaction of peroxydisulphate/peroxymonosulphate with ferrous iron in the SR-AOP systems [105]). It should be noted that this possibility was proposed a long time ago (1932, reported by Bray and Gorin). This phenomenon has also been observed for other metal-activated systems, and day by day, new reports are being written on this topic. 
QCC has addressed this issue, intending to provide any reliable evidence. Buda et al. [106] employed DFT for the investigation of the radical mechanisms in the Fenton reaction. They determined that the departing hydroxyl radical extracts hydrogen from adjacent coordinated water that leads to the formation of a second $\mathrm{Fe}-\mathrm{OH}$ bond and a water molecule instead of the development of a free hydroxyl radical $[104,105]$. The primary intermediate transforms into the $\left[\mathrm{Fe}^{\mathrm{IV}}\left(\mathrm{H}_{2} \mathrm{O}\right)_{4}(\mathrm{OH})_{2}\right]^{2+}$ complex along this reaction path and into a more stable high valent ferryl-oxo complex $\left[\mathrm{Fe}^{\mathrm{IV}}\left(\mathrm{H}_{2} \mathrm{O}\right)_{5} \mathrm{O}\right]^{2+}$ in the second step, which can oxidize further, e.g., organic molecules. Solvent water molecules play a key role in the process [107-109]. A decade later, these conclusions were confirmed [110]. Representative free-energy profiles elucidated the Fenton reaction. The reaction producing ferryl-oxo species from Fenton's reagent was found to be more energetically favourable than the one creating a free hydroxyl radical by $24.4 \mathrm{kcal} / \mathrm{mol}$. This confirmed the previous hypotheses that the primary oxidizing agent in Fenton's reactions is the ferryl-oxo species.

On the other hand, these reactions at a low $\mathrm{pH}$ value were determined theoretically to be dominated by the formation of Fe(III) and hydroxyl radicals [111].

Finally, the authors decided to cross the t's, dot the I's on this matter and studied the reaction at a broader $\mathrm{pH}$ spectrum using DFT methods [112]. The findings indicated that high-valent oxoiron(IV) complexes are the primary Fenton oxidants at $\mathrm{pH}>2.2$, while, as reported earlier, at a $\mathrm{pH}$ of less than 2.2, the contribution of hydroxyl radicals could compete with the species of oxoiron(IV). It was also found that the phosphate buffer (sometimes used to maintain the $\mathrm{pH}$ reaction during AOP) can switch ferryl ion reactions into hydroxyl radicals [104]. Experimentally it was not revealed until very recently; Chen [104] described this mechanism via DFT calculations. He claimed that phosphoric acid anions highly coordinate the iron ion in phosphate buffer solutions. The previouslydiscussed formation of $\mathrm{Fe}(\mathrm{IV})=\mathrm{O}$ species is prevented by proton-transfer reactions that become energetically favourable when the phosphate coordination number goes up to three. Moreover, while phosphate buffers promote the generation of $\bullet \mathrm{OH}$ in the Fenton reaction, phosphoric acid anions can act as $\bullet \mathrm{OH}$ scavengers via hydrogen atom transfer reactions [113].

These investigations show the excellent capability of computational techniques for deciphering large controversies in the environmental chemistry field, caused by reactions which, due to the very fast kinetics, are a challenge to resolved by experimental methods.

\section{Conclusion}

We already know that the suggestion published in 1998 in The Economist [114]: "Turn off that Bunsen burner; it will not be wanted these ten years" was overstated, but what is the situation 23 years later? The answer is, of course, that we need, and will always need, experimental techniques. As Richard Feynman said, "...if it disagrees with experiment it is wrong. That is all there is to it".

However, due to the enormous increase in computational speed, (Moore's law; multiple CPU cores in every new PC, GPU acceleration [115]), QCC is more accurate and accessible to everyone. Comparing experimental and theoretical approaches for determining the reaction energies of complex reactions by DFT can be as close as $\sim 0.4 \mathrm{kcal} / \mathrm{mol}$ [116], which translates to a reasonable error in the determination of kinetic rate constants by TST, i.e., a factor difference of 2 from the experimental value [39]. 
The errors of determining the rate constants by QCC are closing in on those that could be determined experimentally, e.g., by competition kinetics.

Regioselectivity can be determined by many descriptors, such as NBO, ALIE, Fukui functions and dual descriptor. In this paper, an interesting example of the Acid Blue 129 compound was shown. Moreover, QCC can assess product formation by generating UV-Vis, infrared spectra, which can be further compared with experimental results. Many authors already perform QCC solely to evaluate AOP systems. The determined toxicity of the by-product is also assessed by, e.g., Ecological Structure-Activity Relationships models [117], making all the reports "laboratory-free" and comparing the results with ones that can be found in literature.

There are many controversies present in the experimental part of the field of environmental chemistry, which can often be assessed by QCC. In this article, the Fenton mechanism controversy was presented as one example. A recent theoretical study named the most abundant species in the Fenton reaction to be: $\bullet \mathrm{OH}<\mathrm{pH}=2.2<$ oxoiron(IV). However, many unanswered questions remain, such as, what is the exact mechanism of singlet oxygen formation in AOP and SR-AOP? What is the role of superoxide radicals in the degradation of chlorinated contaminants during AOP?

These and many other utilities of QCC can help experimental scientists with the laborious preliminary screening of the desired remediation system for a given case. By this, the work time, the reagents used and waste generated can be substantially reduced, which perfectly fits the principles of green chemistry.

\section{Acknowledgements}

This article was written in honour of my father's long and excellent work on chemical processes in the environment.

\section{Funding}

The author would like to acknowledge the help of the Ministry of Education, Youth and Sports in the Czech Republic under the Research Infrastructures NanoEnviCz (Project No. LM2018124) and "Inter Excellence - Action programme" within the framework of the project "Exploring the role of ferrates and modified nano zero-valent iron in the activation process of persulphates" (reg. nr: LTAUSA18078). This work was also supported by the Ministry of Education, Youth and Sports of the Czech Republic and the European Union European Structural and Investment Funds in the framework of the Operational Programme Research, Development and Education - project Hybrid Materials for Hierarchical Structures (HyHi, Reg. no. CZ.02.1.01/0.0/0.0/16_019/0000843). The author is also gratefully thankful for the support provided by the Grant Agency of the Czech Republic (GA ČR) GJ20-17028Y Nano Zero-Valent Iron and Cyclodextrins - their Synergistic Action for Water Purification.

\section{References}

[1] Crutzen PJ, Wacławek S. Atmospheric chemistry and climate in the anthropocene (Chemia atmosferyczna i klimat w antropocenie). Chem Didact Ecol Metrol. 2015;19:9-28. DOI: 10.1515/cdem-2014-0001.

[2] Wacławek S, Cerník M, Dionysiou DD. The Development and Challenges of Oxidative Abatement for Contaminants of Emerging Concern. A New Paradigm for Environmental Chemistry and Toxicology. Singapore: Springer Singapore; 2020. DOI: 10.1007/978-981-13-9447-8_10. 
[3] Wacławek S, Grübel K, Silvestri D, Padil VVT, Wacławek M, Černík M, et al. Disintegration of wastewater activated sludge (WAS) for improved biogas production. Energies. 2019;12:21. DOI: 10.3390/en12010021.

[4] Silvestri D, Wacławek S, Stejskal V, Vlkova D, Kvapil P, Kohout P, et al. A pilot test in Eastern Bohemia for chlorinated aliphatic hydrocarbons groundwater remediation. CEST'19, 2019. Available from: https://cest2019.gnest.org/sites/default/files/presentation_file_list/cest2019_00918_posterf_paper.pdf.

[5] Grübel K, Machnicka A, Nowicka E, Wacławek S. Mesophilic-thermophilic fermentation process of waste activated sludge after hybrid disintegration. Ecol Chem Eng S. 2014;21:125-36. DOI: 10.2478/eces-2014-0011.

[6] Wacławek S, Grübel K, Chłąd Z, Dudziak M, Černík M. The impact of oxone on disintegration and dewaterability of waste activated sludge. Water Environ Res. 2016;88:152-7. DOI: $10.2175 / 106143016 \times 14504669767139$.

[7] Wacławek S, Grübel K, Černík M. The impact of peroxydisulphate and peroxymonosulphate on disintegration and settleability of activated sludge. Environ Technol (United Kingdom). 2016;37:1296-304. DOI: $10.1080 / 09593330.2015 .1112434$.

[8] Wacławek S, Grübel K, Chład Z, Dudziak M. Impact of peroxydisulphate on disintegration and sedimentation properties of municipal wastewater activated sludge. Chem Pap. 2015;69:1473-80. DOI: 10.1515/chempap-2015-0169.

[9] Wacławek S, Lutze HV, Grübel K, Padil VVT, Černík M, Dionysiou DD. Chemistry of persulfates in water and wastewater treatment: A review. Chem Eng J. 2017;330:44-62. DOI: 10.1016/j.cej.2017.07.132.

[10] Wacławek S, Padil VVT, Černík M. Major advances and challenges in heterogeneous catalysis for environmental applications: A review. Ecol Chem Eng S. 2018;25:9-34. DOI: 10.1515/ECES-2018-0001.

[11] Tsitonaki A, Petri B, Crimi M, Mosbk H, Siegrist RL, Bjerg PL. In situ chemical oxidation of contaminated soil and groundwater using persulfate: A review. Crit Rev Environ Sci Technol. 2010;40:55-91. DOI: $10.1080 / 10643380802039303$.

[12] Tentscher PR, Lee M, von Gunten U. Micropollutant oxidation studied by quantum chemical computations: Methodology and applications to thermodynamics, kinetics, and reaction mechanisms. Acc Chem Res. 2019;52:605-14. DOI: 10.1021/acs.accounts.8b00610.

[13] Tachikawa H, Iyama T, Abe S. DFT study on the interaction of fullerene (C-60) with hydroxyl radical (OH). In: Iwamoto M, Kaneto K, Otomo A, Onoda, M, editors. 9th Int Conf Nano-Molecular Electronics. 2011;14. DOI: 10.1016/j.phpro.2011.05.027.

[14] Pabis A, Szala-Bilnik J, Swiatla-Wojcik D. Molecular dynamics study of the hydration of the hydroxyl radical at body temperature. Phys Chem Chem Phys. 2011;13:9458-68. DOI: 10.1039/c0cp02735a.

[15] Shimizu E, Tokuyama Y, Okutsu N, Nomura K, Danilov VI, Kurita N. Attacking mechanism of hydroxyl radical to DNA base-pair: density functional study in vacuum and in water. J Biomol Struct Dyn. 2015;33:158-66. DOI: 10.1080/07391102.2013.864572.

[16] Yamabe S, Tsuchida N, Yamazaki S. DFT Study of the hydroxyl radical addition to 2'-deoxyguanosine and the guanine base in four double-stranded B-form dimers. J Phys Chem B. 2020;124:1374-82. DOI: 10.1021/acs.jpcb.9b10330.

[17] Liu P, Wang Q, Niu M, Wang D. Multi-level quantum mechanics and molecular mechanics study of ring opening process of guanine damage by hydroxyl radical in aqueous solution. Sci Rep. 2017;7. DOI: 10.1038/s41598-017-08219-z.

[18] Lespade L. Ab initio molecular dynamics of free radical-induced oxidation of ergothioneine. J Mol Model. 2019;25. DOI: 10.1007/s00894-019-4220-3.

[19] Koppenol WH. Oxygen activation by cytochrome P450: A thermodynamic analysis. J Am Chem Soc. 2007;129:9686-90. DOI: 10.1021/ja071546p.

[20] Espinosa-Garcia J, Gutierrez-Merino C. The trapping of the $\mathrm{OH}$ radical by coenzyme Q. A theoretical and experimental study. J Phys Chem A. 2003;107:9712-23. DOI: 10.1021/jp035927a.

[21] Hatipoglu A, Vione D, Yalcin Y, Minero C, Cinar Z. Photo-oxidative degradation of toluene in aqueous media by hydroxyl radicals. J Photochem Photobiol A: Chemistry. 2010;215:59-68. DOI: 10.1016/j.jphotochem.2010.07.021.

[22] Asghar A, Abdul Raman AA, Wan Daud WMA, Ramalingam A. Reactivity, stability, and thermodynamic feasibility of $\mathrm{H}_{2} \mathrm{O}_{2} / \mathrm{H}_{2} \mathrm{O}$ at graphite cathode: Application of quantum chemical calculations in MFCs. Environ Prog Sustain Energy. 2018;37:1291-304. DOI: 10.1002/ep.12806.

[23] Hanwell MD, Curtis DE, Lonie DC, Vandermeersch T, Zurek E, Hutchison GR. Avogadro: an advanced semantic chemical editor, visualization, and analysis platform. J Cheminform. 2012;4:17. DOI: 10.1186/1758-2946-4-17.

[24] Neese F. The ORCA program system. WIREs Comput Mol Sci. 2012;2:73-8. DOI: 10.1002/wcms.81.

[25] Frisch MJ, Trucks GW, Schlegel HB, Scuseria GE, Robb M, Cheeseman JR, et al. Gaussian 16_C01 2016. Available from: https://gaussian.com/. 
[26] Lu T, Chen F. Atomic dipole moment corrected Hirshfeld population method. J Theor Comput Chem. 2012;11:163-83. DOI: 10.1142/S0219633612500113.

[27] Luo S, Gao L, Wei Z, Spinney R, Dionysiou DD, Hu WP, et al. Kinetic and mechanistic aspects of hydroxyl radical-mediated degradation of naproxen and reaction intermediates. Water Res. 2018;137:233-41. DOI: 10.1016/j.watres.2018.03.002.

[28] Krawczyk K, Wacławek S, Kudlek E, Silvestri D, Kukulski T, Grübel K, et al. UV-catalyzed persulfate oxidation of an anthraquinone based dye. Catalysts. 2020;10:456. DOI: 10.3390/catal10040456.

[29] Lu T, Chen F. Multiwfn: A multifunctional wavefunction analyzer. J Comput Chem. 2012;33:580-92. DOI: $10.1002 / \mathrm{jcc} .22885$.

[30] Humphrey W, Dalke A, Schulten K. VMD: Visual molecular dynamics. J Mol Graph. 1996;14:33-8. DOI: 10.1016/0263-7855(96)00018-5.

[31] VMD a molecular visualization program, Webpage. Available from: http://www.ks.uiuc.edu/Research/vmd/.

[32] Toro-Labbé A, Jaque P, Murray JS, Politzer P. Connection between the average local ionization energy and the Fukui function. Chem Phys Lett. 2005;407:143-6. DOI: 10.1016/j.cplett.2005.03.041.

[33] Johnson N, Russell I. Advances in Wool Technology. Woodhead Publishing Ltd.; 2008. ISBN: 9781845693329. Available from: http://hdl.handle.net/2086/9354.

[34] Cinar Z. The role of molecular modeling in $\mathrm{TiO}_{2}$ photocatalysis. Molecules. 2017;22:556. DOI: 10.3390/molecules22040556.

[35] Zhang S, Yu G, Chen J, Zhao Q, Zhang X, Wang B, et al. Elucidating ozonation mechanisms of organic micropollutants based on DFT calculations: Taking sulfamethoxazole as a case. Environ Pollut. 2017;220:971-80. DOI: 10.1016/J.ENVPOL.2016.10.076.

[36] Psutka JM, Dion-Fortier A, Dieckmann T, Campbell JL, Segura PA, Hopkins WS. Identifying Fenton-reacted trimethoprim transformation products using differential mobility spectrometry. Anal Chem. 2018;90:5352-7. DOI: 10.1021/acs.analchem.8b00484.

[37] Lecours MA, Eysseric E, Yargeau V, Lessard J, Brisard G, Segura P, et al. Electrochemistry-high resolution mass spectrometry to study oxidation products of trimethoprim. Environments. 2018;5:18. DOI: 10.3390/environments5010018.

[38] Dittmer A, Izsák R, Neese F, Maganas D. Accurate band gap predictions of semiconductors in the framework of the similarity transformed equation of motion coupled cluster theory. Inorg Chem. 2019;58:9303-15. DOI: 10.1021/acs.inorgchem.9b00994.

[39] Kamath D, Mezyk SP, Minakata D. Elucidating the elementary reaction pathways and kinetics of hydroxyl radical-induced acetone degradation in aqueous phase advanced oxidation processes. Environ Sci Technol. 2018;52:7763-74. DOI: 10.1021/acs.est.8b00582.

[40] Maeda S, Harabuchi Y, Ono Y, Taketsugu T, Morokuma K. Intrinsic reaction coordinate: Calculation, bifurcation, and automated search. Int J Quantum Chem. 2015;115:258-69. DOI: 10.1002/qua.24757.

[41] Serobatse KRN, Kabanda MM. An appraisal of the hydrogen atom transfer mechanism for the reaction between thiourea derivatives and center dot $\mathrm{OH}$ radical: A case-study of dimethylthiourea and diethylthiourea. Comput Theor Chem. 2017;1101:83-95. DOI: 10.1016/j.comptc.2016.12.027.

[42] Moc J, Simmie JM. Hydrogen abstraction from n-butanol by the hydroxyl radical: high level ab initio study of the relative significance of various abstraction channels and the role of weakly bound intermediates. J Phys Chem A. 2010;114:5558-64. DOI: 10.1021/jp1009065.

[43] Cinar SA, Ziylan-Yavas A, Catak S, Ince NH, Aviyente V. Hydroxyl radical-mediated degradation of diclofenac revisited: a computational approach to assessment of reaction mechanisms and by-products. Environ Sci Pollut Res. 2017;24:18458-69. DOI: 10.1007/s11356-017-9482-7.

[44] Canneaux S, Bohr F, Henon E. KiSThelP: A program to predict thermodynamic properties and rate constants from quantum chemistry results. J Comput Chem. 2014;35:82-93. DOI: 10.1002/jcc.23470.

[45] Aydogdu S, Hatipoglu A. Theoretical investigation on the kinetics of dimethyl phosphoramidate with hydroxyl radicals. J Indian Chem Soc. 2019;96:1117-22.

[46] Xiao R, Gao L, Wei Z, Spinney R, Luo S, Wang D, et al. Mechanistic insight into degradation of endocrine disrupting chemical by hydroxyl radical: An experimental and theoretical approach. Environ Pollut. 2017;231:1446-52. DOI: 10.1016/j.envpol.2017.09.006.

[47] Li X, Wang B, Wang Y, Li K, Yu G. Synergy effect of E-peroxone process in the degradation of structurally diverse pharmaceuticals: A QSAR analysis. Chem Eng J. 2019;360:1111-8. DOI: 10.1016/J.CEJ.2018.10.191.

[48] Sudhakaran S, Calvin J, Amy GL. QSAR models for the removal of organic micropollutants in four different river water matrices. Chemosphere. 2012;87:144-50. DOI: 10.1016/J.CHEMOSPHERE.2011.12.006.

[49] Lee Y, von Gunten U. Quantitative structure-activity relationships (QSARs) for the transformation of organic micropollutants during oxidative water treatment. Water Res. 2012;46:6177-95. DOI: 10.1016/J.WATRES.2012.06.006. 
[50] Luo S, Wei Z, Dionysiou DD, Spinney R, Hu WP, Chai L, et al. Mechanistic insight into reactivity of sulfate radical with aromatic contaminants through single-electron transfer pathway. Chem Eng J. 2017;327:1056-65. DOI: 10.1016/j.cej.2017.06.179.

[51] Liu Y, Cheng Z, Liu S, Tan Y, Yuan T, Yu X, et al. Quantitative structure activity relationship (QSAR) modelling of the degradability rate constant of volatile organic compounds (VOCs) by $\mathrm{OH}$ radicals in atmosphere. Sci Total Environ. 2020;729:138871. DOI: 10.1016/j.scitotenv.2020.138871.

[52] Sudhakaran S, Amy GL. QSAR models for oxidation of organic micropollutants in water based on ozone and hydroxyl radical rate constants and their chemical classification. Water Res. 2013;47:1111-22. DOI: 10.1016/j.watres.2012.11.033.

[53] Luo X, Wei X, Chen J, Xie Q, Yang X, Peijnenburg WJGM. Rate constants of hydroxyl radicals reaction with different dissociation species of fluoroquinolones and sulfonamides: Combined experimental and QSAR studies. Water Res. 2019;166. DOI: 10.1016/j.watres.2019.115083.

[54] Jia L, Shen Z, Guo W, Zhang Y, Zhu H, Ji W, et al. QSAR models for oxidative degradation of organic pollutants in the Fenton process. J Taiwan Inst Chem Eng. 2015;46:140-7. DOI: 10.1016/J.JTICE.2014.09.014.

[55] Su H, Yu C, Zhou Y, Gong L, Li Q, Alvarez PJJ, et al. Quantitative structure-activity relationship for the oxidation of aromatic organic contaminants in water by $\mathrm{TAML} / \mathrm{H}_{2} \mathrm{O}_{2}$. Water Res. 2018;140:354-63. DOI: 10.1016/J.WATRES.2018.04.062.

[56] Cheng Z, Yang B, Chen Q, Tan Y, Gao X, Yuan T, et al. 2D-QSAR and 3D-QSAR simulations for the reaction rate constants of organic compounds in ozone-hydrogen peroxide oxidation. Chemosphere. 2018;212:828-36. DOI: 10.1016/J.CHEMOSPHERE.2018.08.097.

[57] Gupta S, Basant N. Modeling the $\mathrm{pH}$ and temperature dependence of aqueousphase hydroxyl radical reaction rate constants of organic micropollutants using QSPR approach. Environ Sci Pollut Res. 2017;24:24936-46. DOI: 10.1007/s11356-017-0161-5.

[58] Heeb MB, Criquet J, Zimmermann-Steffens SG, von Gunten U. Oxidative treatment of bromide-containing waters: Formation of bromine and its reactions with inorganic and organic compounds - A critical review. Water Res. 2014;48:15-42. DOI: 10.1016/J.WATRES.2013.08.030.

[59] Lee H, Park SH, Kim BH, Kim SJ, Kim SC, Seo SG, et al. Contribution of dissolved oxygen to methylene blue decomposition by hybrid advanced oxidation processes system. Int J Photoenergy. 2012;2012:1-6. DOI: $10.1155 / 2012 / 305989$.

[60] Zhang R, Wang X, Zhou L, Liu Z, Crump D. The impact of dissolved oxygen on sulfate radical-induced oxidation of organic micro-pollutants: A theoretical study. Water Res. 2018;135:144-54. DOI: 10.1016/J.WATRES.2018.02.028.

[61] Xie Y, Schaefer HF. Hydrogen bonding between the water molecule and the hydroxyl radical $\left(\mathrm{H}_{2} \mathrm{O} \cdot \mathrm{HO}\right)$ : The global minimum. J Chem Phys. 1993;98:8829-34. DOI: 10.1063/1.464492.

[62] Kim KS, Kim HS, Jang JH, Kim HS, Mhin BJ, Xie Y, et al. Hydrogen bonding between the water molecule and the hydroxyl radical $\left(\mathrm{H}_{2} \mathrm{O} \cdot \mathrm{OH}\right)$ : The $2 \mathrm{~A}^{\prime \prime}$ and $2 \mathrm{~A}^{\prime}$ minima. J Chem Phys. 1991;94:2057-62. DOI: 10.1063/1.459927.

[63] Dubey MK, Mohrschladt R, Donahue NM, Anderson JG. Isotope specific kinetics of hydroxyl radical $(\mathrm{OH})$ with water $\left(\mathrm{H}_{2} \mathrm{O}\right)$ : Testing models of reactivity and atmospheric fractionation. $J$ Phys Chem A. 1997;101:1494-500. DOI: 10.1021/jp962332p.

[64] Vassilev P, Louwerse MJ, Baerends EJ. Hydroxyl radical and hydroxide ion in liquid water: A comparative electron density functional theory study. J Phys Chem B. 2005;109:23605-10. DOI: 10.1021/jp044751p.

[65] Allodi MA, Dunn ME, Livada J, Kirschner KN, Shields GC. Do hydroxyl radical-water clusters, $\mathrm{OH}\left(\mathrm{H}_{2} \mathrm{O}\right)(\mathrm{n}), \mathrm{n}=1-5$, exist in the atmosphere? J Phys Chem A. 2006;110:13283-9. DOI: 10.1021/jp0644681.

[66] Belair SD, Francisco JS, Singer SJ. Hydrogen bonding in cubic (H2O)(8) and OH center $\operatorname{dot}((\mathrm{HO})-\mathrm{O}-2)(7)$ clusters. Phys Rev A. 2005;71. DOI: 10.1103/PhysRevA.71.013204.

[67] Voglozin D, Cooper P. Altitude profile of the OH radical complex with water in Earth's atmosphere: a quantum mechanical approach. J Atmos Chem. 2017;74:475-89. DOI: 10.1007/s10874-016-9353-5.

[68] Park JH. Ab initio study on the complex forming reaction of $\mathrm{OH}$ and $\mathrm{H}_{2} \mathrm{O}$ in the gas phase. Asian $\mathrm{J}$ Atmos Environ. 2015;9:158-64. DOI: 10.5572/ajae.2015.9.2.158.

[69] Schofield DP, Kjaergaard HG. High-level ab initio studies of the electronic excited states of the hydroxyl radical and water-hydroxyl complex. J Chem Phys. 2004;120:6930-4. DOI: 10.1063/1.1687335.

[70] Soloveichik P, O’Donnell BA, Lester MI, Francisco JS, McCoy AB. Infrared spectrum and stability of the $\mathrm{H}_{2} \mathrm{O}-\mathrm{HO}$ complex: Experiment and theory. J Phys Chem A. 2010;114:1529-38. DOI: 10.1021/jp907885d.

[71] Crespo-Otero R, Sanchez-Garcia E, Suardiaz R, Montero LA, Sander W. Interactions between simple radicals and water. Chem Phys. 2008;353:193-201. DOI: 10.1016/j.chemphys.2008.08.012. 
[72] Zhou Z, Qu Y, Fu A, Du B, He F, Gao H. Density functional complete study of hydrogen bonding between the water molecule and the hydroxyl radical $\left(\mathrm{H}_{2} \mathrm{O}\right.$ - HO). Int J Quantum Chem. 2002;89:550-8. DOI: 10.1002/qua.10315.

[73] Gonzalez J, Anglada JM. Gas phase reaction of nitric acid with hydroxyl radical without and with water. A theoretical investigation. J Phys Chem A. 2010;114:9151-62. DOI: 10.1021/jp102935d.

[74] Buszek RJ, Torrent-Sucarrat M, Anglada JM, Francisco JS. Effects of a single water molecule on the $\mathrm{OH}+\mathrm{H}_{2} \mathrm{O}_{2}$ reaction. J Phys Chem A. 2012;116:5821-9. DOI: $10.1021 / \mathrm{jp} 2077825$.

[75] Domin D, Braida B, Berges J. Influence of water on the oxidation of dimethyl sulfide by the (OH)-O-center dot radical. J Phys Chem B. 2017;121:9321-30. DOI: 10.1021/acs.jpcb.7b05796.

[76] Marenich AV, Cramer CJ, Truhlar DG. Universal solvation model based on solute electron density and on a continuum model of the solvent defined by the bulk dielectric constant and atomic surface tensions. J Phys Chem B. 2009;113:6378-96. DOI: 10.1021/jp810292n.

[77] Manonmani G, Sandhiya L, Senthilkumar K. Mechanism and kinetics of diuron oxidation initiated by hydroxyl radical: hydrogen and chlorine atom abstraction reactions. J Phys Chem A. 2019;123:8954-67. DOI: 10.1021/acs.jpca.9b04800.

[78] Minakata D, Crittenden J. Linear free energy relationships between aqueous phase hydroxyl radical reaction rate constants and free energy of activation. Environ Sci Technol. 2011;45:3479-86. DOI: 10.1021/es1020313.

[79] Codorniu-Hernandez E, Kusalik PG. Insights into the solvation and mobility of the hydroxyl radical in aqueous solution. J Chem Theory Comput. 2011;7:3725-32. DOI: 10.1021/ct200418e.

[80] Karakus N, Ozkan R. Ab initio study of atmospheric reactions of the hydroxyl radical-water complex $\left(\mathrm{OH}-\mathrm{H}_{2} \mathrm{O}\right)$ with saturated hydrocarbons (methane, ethane and propane). J Mol Struct. 2005;724:39-44. DOI: 10.1016/j.theochem.2004.10.075.

[81] Mansergas A, Gonzalez J, Ruiz-Lopez M, Anglada JM. The gas phase reaction of carbonyl oxide with hydroxyl radical in presence of water vapor. A theoretical study on the reaction mechanism. Comput Theor Chem. 2011;965:313-20. DOI: 10.1016/j.comptc.2011.02.023.

[82] Gonzalez J, Anglada JM, Buszek RJ, Francisco JS. Impact of water on the $\mathrm{OH}$ plus $\mathrm{HOCl}$ reaction. J Am Chem Soc. 2011;133:3345-53. DOI: 10.1021/ja100976b.

[83] Liu P, Li C, Wang S, Wang D. Catalytic effect of aqueous solution in water-assisted proton-transfer mechanism of 8-hydroxy guanine radical. J Phys Chem B. 2018;122:3124-32. DOI: 10.1021/acs.jpcb.7b09965.

[84] Suma K, Sumiyoshi Y, Endo Y. The rotational spectrum and structure of the HOOO radical. Science. 2005;308:1885-6. DOI: 10.1126/science.1112233.

[85] Gmurek M, Olak-Kucharczyk M, Ledakowicz S. Photochemical decomposition of endocrine disrupting compounds - A review. Chem Eng J. 2017;310:437-56. DOI: 10.1016/j.cej.2016.05.014.

[86] Duan X, Sun H, Wang S. Metal-free carbocatalysis in advanced oxidation reactions. Acc Chem Res. 2018;51:678-87. DOI: 10.1021/acs.accounts.7b00535.

[87] Fan J, Qin H, Jiang S. Mn-doped g-C3N4 composite to activate peroxymonosulfate for acetaminophen degradation: The role of superoxide anion and singlet oxygen. Chem Eng J. 2019;359:723-32. DOI: 10.1016/j.cej.2018.11.165.

[88] Lee J, von Gunten U, Kim JH. Persulfate-based advanced oxidation: Critical assessment of opportunities and roadblocks. Environ Sci Technol. 2020;54:3064-81. DOI: 10.1021/acs.est.9b07082.

[89] Codorniu-Hernandez E, Hall KW, Boese AD, Ziemianowicz D, Carpendale S, Kusalik PG. Mechanism of $\mathrm{O}(\mathrm{P}-3)$ formation from a hydroxyl radical pair in aqueous solution. $\mathbf{J}$ Chem Theory Comput. 2015;11:4740-8. DOI: 10.1021/acs.jctc.5b00783.

[90] Howell CD, Michelangeli DV, Allen M, Yuk LY, Thomas RJ. SME observations of O2 (1 $\Delta \mathrm{g})$ nightglow: An assessment of the chemical production mechanisms. Planet Space Sci. 1990;38:529-37. DOI: 10.1016/0032-0633(90)90145-G.

[91] Vlasov MN, Klopovsky KS, Lopaev DV, Popov NA, Rakhimov AT, Rakhimova TV. The mechanism of singlet oxygen emission in the upper atmosphere. Cosm Res. 1997;35:219-25.

[92] Tarasick DW, Evans WFJ. A review of the $\mathrm{O} 2(\mathrm{a} 1 \Delta \mathrm{g})$ and $\mathrm{O} 2(\mathrm{~b} 1 \Sigma \mathrm{g}+)$ airglow emissions. Adv Sp Res. 1993;13:145-8. DOI: 10.1016/0273-1177(93)90014-3.

[93] Zakharov II, Loriya MG, Tselishchev AB. Structure of the HOO-N=N-OOH intermediate in hydrogen peroxide activation of N2: Quantum chemical DFT calculations. J Struct Chem. 2013;54:10-6. DOI: 10.1134/S0022476613010022.

[94] Wang B, Hou H, Gu Y. Existence of hydrogen bonding between the hydroxyl radical and hydrogen peroxide: $\mathrm{OH} \cdot \mathrm{H}_{2} \mathrm{O}_{2}$. Chem Phys Lett. 1999;309:274-8. DOI: 10.1016/S0009-2614(99)00686-7.

[95] Yamaguchi M. Hemibonding of hydroxyl radical and halide anion in aqueous solution. J Phys Chem A. 2011;115:14620-8. DOI: 10.1021/jp2063386. 
[96] Sevilla MD, Summerfield S, Eliezer I, Rak J, Symons MCR. Interaction of the chlorine atom with water: ESR and ab initio MO evidence for three-electron (sigma(2)sigma $\left\{{ }^{*}\right\}(1)$ ) bonding. J Phys Chem A. 1997;101:2910-5. DOI: 10.1021/jp964097g.

[97] Shah S, Hao C. Quantum chemical investigation on photodegradation mechanisms of sulfamethoxypyridazine with dissolved inorganic matter and hydroxyl radical. J Environ Sci. 2017;57:85-92. DOI: $10.1016 /$ j.jes.2016.09.023.

[98] O’Donnell BA, Li EXJ, Lester MI, Francisco JS. Spectroscopic identification and stability of the intermediate in the $\mathrm{OH}+\mathrm{HONO}_{2}$ reaction. Proc Natl Acad Sci USA. 2008;105:12678-83. DOI: 10.1073/pnas.0800320105.

[99] Martins-Costa MTC, Ruiz-Lopez MF. Molecular dynamics of hydrogen peroxide in liquid water using a combined quantum/classical force field. Chem Phys. 2007;332:341-7. DOI: 10.1016/j.chemphys.2006.12.018.

[100] Jin X, Peldszus S, Huck PM. Reaction kinetics of selected micropollutants in ozonation and advanced oxidation processes. Water Res. 2012;46:6519-30. DOI: 10.1016/J.WATRES.2012.09.026.

[101] Barbusinski K. Fenton reaction - Controversy concerning the chemistry. Ecol Chem Eng S. 2009;16:347-58. Available from: https://drive.google.com/file/d/16kMQeMGRupbWPc4yhlKh48Uy2wH3g2vG/view.

[102] Kuznetsov ML, Teixeira FA, Bokach NA, Pombeiro AJL, Shul'pin GB. Radical decomposition of hydrogen peroxide catalyzed by aqua complexes $\{[\} \mathrm{M}(\mathrm{H} 2 \mathrm{O})(\mathrm{n})](2+)(\mathrm{M}=\mathrm{Be}, \mathrm{Zn}, \mathrm{Cd})$. J Catal. 2014;313:135-48. DOI: 10.1016/j.jcat.2014.03.010.

[103] Novikov AS, Kuznetsov ML, Pombeiro AJL, Bokach NA, Shul'pin GB. Generation of HO center dot radical from hydrogen peroxide catalyzed by aqua complexes of the group III metals $\{[\} \mathrm{M}(\mathrm{H} 2 \mathrm{O})(\mathrm{n})](3+)(\mathrm{M}=\mathrm{Ga}$, In, Sc, Y, or La): A theoretical study. ACS Catal. 2013;3:1195-208. DOI: 10.1021/cs400155q.

[104] Chen HY. Why the reactive oxygen species of the fenton reaction switches from oxoiron(IV) species to hydroxyl radical in phosphate buffer solutions? A Computational Rationale. ACS Omega. 2019;4:14105-13. DOI: 10.1021/acsomega.9b02023.

[105] Duan X, Yang S, Wacławek S, Fang G, Xiao R, Dionysiou DD. Limitations and prospects of sulfate-radical based advanced oxidation processes. J Environ Chem Eng. 2020;8:103849. DOI: 10.1016/j.jece.2020.103849.

[106] Buda F, Ensing B, Gribnau MCM, Baerends EJ. DFT study of the active intermediate in the Fenton reaction. Chem Eur J. 2001;7:2775-83. DOI: 10.1002/1521-3765(20010702)7:13<2775::AID-CHEM2775>3.0.CO; 2-6.

[107] Ensing B, Buda F, Blöchl PE, Baerends EJ. A Car-Parrinello study of the formation of oxidizing intermediates from Fenton's reagent in aqueous solution. Phys Chem Chem Phys. 2002;4:3619-27. DOI: $10.1039 / \mathrm{b} 201864 \mathrm{k}$.

[108] Ensing B, Baerends EJ. Reaction path sampling of the reaction between iron(II) and hydrogen peroxide in aqueous solution. J Phys Chem A. 2002;106:7902-10. DOI: 10.1021/jp0258331.

[109] Ensing B, Buda F, Blöchl P, Baerends EJ. Chemical involvement of solvent water molecules in elementary steps of the Fenton oxidation reaction. Angew Chemie. 2001;113:2977-9. DOI: 10.1002/1521-3757(20010803)113:15<2977::aid-ange2977>3.0.co;2-q.

[110] Yamamoto N, Koga N, Nagaoka M. Ferryl-oxo species produced from Fenton's reagent via a two-step pathway: Minimum free-energy path analysis. J Phys Chem B. 2012;116:14178-82. DOI: 10.1021/jp310008z.

[111] Petit AS, Pennifold RCR, Harvey JN. Electronic structure and formation of simple ferryloxo complexes: Mechanism of the Fenton reaction. Inorg Chem. 2014;53:6473-81. DOI: 10.1021/ic500379r.

[112] Lu HF, Chen HF, Kao CL, Chao I, Chen HY. A computational study of the Fenton reaction in different $\mathrm{pH}$ ranges. Phys Chem Chem Phys. 2018;20:22890-901. DOI: 10.1039/C8CP04381G.

[113] Lutze HV, Brekenfeld J, Naumov S, von Sonntag C, Schmidt TC. Degradation of perfluorinated compounds by sulfate radicals - New mechanistic aspects and economical considerations. Water Res. 2018;129:509-19. DOI: $10.1016 /$ j.watres.2017.10.067.

[114] The 1998 Nobel Prizes. Econ. 1998:97. Available from: https://www.economist.com/science-andtechnology/1998/10/15/picking-winners

[115] Liu F, Sanchez DM, Kulik HJ, Martínez TJ. Exploiting graphical processing units to enable quantum chemistry calculation of large solvated molecules with conductor-like polarizable continuum models. Int J Quantum Chem. 2019;119:e25760. DOI: 10.1002/qua.25760.

[116] Cheng J, Hu D, Yao A, Gao Y, Asadi H. A computational study on the Pd-decorated ZnO nanocluster for $\mathrm{H}_{2}$ gas sensing: A comparison with experimental results. Phys E Low-Dimensional Syst Nanostructures. 2020;124:114237. DOI: 10.1016/j.physe.2020.114237.

[117] Mei Q, Cao H, Han D, Li M, Yao S, Xie J, et al. J Hazard Mater. 2020;389:121901. DOI: 10.1016/j.jhazmat.2019.121901. 